\title{
Study on the Application of Computer-Aided Translation (CAT) in Translation Teaching*
}

\author{
ZHOU Wei \\ Harbin Engineering University, Harbin, China
}

\author{
GAO Bei \\ East College of Heilongjiang, Harbin, China
}

\begin{abstract}
By briefly overviewing the definition and core techniques of CAT, this paper discusses the application of CAT in translation teaching, aiming to explore the necessity and defects of the application. Some suggestions are also proposed by the author. The author believes that the application of CAT technology in translation teaching will be increasingly vital day by day, and the defects will be overcome with the growing awareness. The emergence of Computer Aided Translation (CAT) technology has relieved work pressure and increased the efficiency. Great importance should be paid on the application of CAT in translation teaching.
\end{abstract}

Keywords: Computer Aided Translation (CAT), application, translation teaching

\section{Introduction}

In recent years, with the increasingly rapid development of economic globalization and advance in science and technology, translating field encounters unprecedented impact. Translators are asked not only higher speed but also higher quality. Meanwhile, translation teaching faces enormous challenges. Under the traditional teaching mode, students cannot meet the great social demand. Thanks to the prosperity of technology, Computer Aided Translation (CAT) has emerged as the time requires.

Speaking of Computer-Aided Translation (CAT), it is necessary to mention Machine Translation in the first place. It is not only because many people confound the definition of the two terms, but also because CAT grew out of Machine Translation. Machine translation, which can be abbreviated as MT and also called automated translation, is a sub-field of computational linguistics that investigates the use of computer software to translate text or speech from one natural language to another (Wikipedia). MT is a full automatic translation process. The dominant strategy of MT is utilizing intermediary representation to make indirect translation come true. Due to the difference of core technology and algorithm, MT could be classified in many types, such as rule-based MT, statistic-based MT and so on. MT leaves out the process of looking up referent material and pondering, so the speed of it is surprisingly faster than human translation. However, as time went on, people found that MT has its limitations. First of all, it can only understand the literal meaning instead of metaphorical meaning. As a result of

\footnotetext{
${ }^{*}$ Acknowledgements: This paper was supported by "The Research Project of Heilongjiang Province Economic and Social Development (The Special Project for Foreign Languages Discipline)" (Grant No. WY2016036-B), "Fundamental Research Funds for the Central Universities" (Grant No. GK2130260106), and "Education Reform Project of Harbin Engineering University" (Grant No. JG2013YB55).

ZHOU Wei, associate professor, master, Department of Foreign Languages, Harbin Engineering University.

GAO Bei, lecturer, master, Section of College English, East College of Heilongjiang.
} 
this defect, some texts, for example, which contain amounts of proverbs, cannot be translated accurately. Secondly, MT cannot recognize various context. As we know, different contexts need different expression. Usually, political texts should be translated with formal terms while the dialogue between parents and children should be translated with informal words. However, MT cannot select which word is suitable on the basis of context. Thirdly, though MT is based on grammar rules or sentences, when the original text is too long to be divided, MT will have a tendency to translate word by word and sentence by sentence.

Example (1)

Original text: This function causes sliding roof to open or close.

Machine translation: 这个功能引起滑动屋顶打开(或者关闭)。

Correct translation: 该功能可使滑动天窗打开(或关闭)。(LI \& ZHU, 2013, pp. 83-87)

It is obvious that the second translation is more accurate than the first one. With the increasing demand for the quality of translation, the MT systems available are not able to produce high quality translations unaided: Their output must be edited by human to correct errors and improve the quality of translation. People have realized that human being should be the main part of translation. Therefore, CAT was born and gradually becomes a hot topic at home and abroad.

\section{Brief Overview on CAT}

\section{The Definition of CAT}

Computer Aided Translation, sometimes also called Computer Assisted Translation and abbreviated as CAT, has a rapidly developed history in the world. In a broad sense, CAT refers to a type of translation process during which translators take advantage of all kinds of computer applications as aiding tools to help them complete the translation work with high efficiency and high quality. In a narrow sense, CAT refers to the software and system optimized in connection with translation process (CHEN, 2011, p. 3).

CAT is also called semiautomatic translation. In CAT, translators are responsible for the process of translation, but they may make use of a variety of computerized tools to help them complete the task and increase their productivity (Bowker, 2002, p. 32).

\section{Two Core Techniques of CAT}

Two core supporting techniques of CAT are translation memory and terminology database. They are two complementary techniques of CAT technology.

A translation memory is a type of linguistic database that is used to store source texts and the target translations. The texts are broken down into short segments that often correspond to sentences (Bowker, 2002, p. 92). Translation memory is a core technique of CAT technology. The major function of it is to store language units as the work goes along and retrieves quickly when the same or familiar units appear again. Nowadays, translation memory is very useful for the huge translating market. With the development of science and technology, more and more professional text such as technical and commercial texts need to be translated. Most of them contains amounts of repetitive language. In different industries and sectors, such material repetition appears to $20 \%-70 \%$ range, which means that at least $20 \%$ of the interpreter's work is meaningless duplication (QIAN, 2011, p. 100). It is no doubt that repetitive work is time-consuming. Translation memory can do a lot of favor in this aspect. However, it still has some limitations. Some types of articles contains few repetitive 
discourses and language segments, such as literature text. Translation memory is less helpful when translators translate these texts.

Translation memory works for the equivalence of sentence or discourse, while the bilingual terminology database which is formed by the professional terminology ensures the consistency of translated tasks (QIAN, 2011, p. 94).

Besides translation memory, terminology database is another important supporting technique of CAT. A terminology management system is a helpful technique in various aspects of the translator's terminology related tasks, including the storage, retrieval, and updating of term records (Bowker, 2002, p. 77). Terminology database is helpful for increasing efficiency and quality of translation. For one thing, it is a good way to save time. Previously, translators have to recite a great number of terms in order to translate professional text at high speed. In addition, because it is impossible to remember all terms in the world, translators still need the assistance of various dictionaries. Both reciting and looking for dictionaries are time-consuming. Nowadays, with the help of terminology database, the translators just need input the text into computer aided translation software, and all of existing terms will automatically generate. For another, terminology database can ensure the consistency of text. A word in one language may have many corresponding translation in another language. When translation is carried out by many people at the same time, keeping the same translation is very difficult. It can help translators select the most suitable translation and keep it as translation goes along. However, it is a difficult problem to build a comprehensive terminology database in a short time. It has confused translators and linguists all the time because of the numerous terms. At the same time, the increase in the number of new foreign words causes the terminology database should be always renewed and modified.

Some utility software of CAT technology has appeared in recent years. Trados, Dejavu are more famous. More and more translator teams and companies pay attention to these aided tools. It is imperative for universities to set up relevant translation courses about CAT.

\section{Studies of CAT in China}

In China, more and more specialists have paid attention to CAT. In recent years, CAT gradually shows a trend of integration of translation teaching. In 1985, the First National College Foreign Language Audio-visual Conference was held in Beijing, in which a large number of monographs on CALL (Computer-Aided Language Learning) were presented and softwares on CALL were displayed. In 2002, The Chinese University of Hong kong set up the first course of Computer Aided Translation Master in the world (REN, 2010, p. 15). In April 2007, Peking University established "Computer-Aided Translation Seminar" (ZUO, 2010, pp. 136-137). In 2009, Peking University offered master degree of CAT. However, the academia's concern for CAT is still far away from enough. Take the published articles for instance. 
Table 1

Statistics From Three Prominent Translation Journals (CHEN, 2011, p. 33)

\begin{tabular}{lllllll}
\hline & \multicolumn{2}{c}{ Chinese Translations Journal } & \multicolumn{2}{c}{ Shanghai Journal of Translators } & \multicolumn{2}{c}{$\begin{array}{c}\text { Chinese Science \& Technology } \\
\text { Translators Journal }\end{array}$} \\
\cline { 2 - 7 } & $\begin{array}{l}\text { Number of } \\
\text { articles in total }\end{array}$ & $\begin{array}{l}\text { Number of articles } \\
\text { about CAT/CAT } \\
\text { software }\end{array}$ & $\begin{array}{l}\text { Number of articles } \\
\text { in total }\end{array}$ & $\begin{array}{l}\text { Number of articles } \\
\text { about CAT/CAT } \\
\text { software }\end{array}$ & $\begin{array}{l}\text { Number of articles } \\
\text { in total }\end{array}$ & $\begin{array}{l}\text { Number of articles } \\
\text { about CAT/CAT } \\
\text { software }\end{array}$ \\
\hline 2010 & 116 & 1 & 76 & 3 & 69 & 0 \\
2009 & 118 & 1 & 77 & 0 & 68 & 0 \\
2008 & 130 & 0 & 78 & 0 & 72 & 0 \\
2007 & 132 & $0 *$ & 81 & 0 & 71 & 0 \\
2006 & 134 & 1 & 88 & 0 & 73 & 0 \\
2005 & 144 & 0 & 124 (S1 included) & & 73 & 1 \\
2004 & 153 & 0 & 81 & 0 & 74 & 0 \\
2003 & 152 & 0 & 97 & 0 & 72 & 4 \\
2002 & 175 & 0 & 80 & 2 & 74 & 4 \\
2001 & 136 & 0 & 69 & 0 & & 4 \\
\hline
\end{tabular}

It shows the total number of articles and those on CAT/CAT software in the three prominent translation journals during the years from 2001 to 2010 . We can see from the Table 1 that in the three prominent translation journals, the number of articles about translation is abundant, but the proportion of articles about CAT is very small and almost close to zero. From 2006 to 2010, Chinese translation journal gradually pays attention to CAT, and Shanghai Journal of Translators has published three articles about CAT in 2010. It is a huge improvement in quantity than before, while Chinese Science \& Technology Translators Journal has no obvious change in recent years. CAT still has a long way to go in China.

\section{CAT and Translation Teaching in China}

\section{The Necessity of CAT's Application in Translation Teaching}

Thanks to the development of science and technology, work efficiency of all walks has improved a lot. Social demands for each field also increase rapidly. For translators, completely artificial translation cannot conform to the requirement of the times. They need depend on technology to achieve their tasks. For students, who major in translation, studying relevant technology is necessary during their school time.

\section{CAT Technology Meets the Social Demands}

Nowadays, globalization is the irreversible trend in the world. International cooperation occurs everyday among companies, schools, even nations. As a requisite group for today's society, translators are bearing severe challenges. What is more, the students who major in translation will face heavier pressure when they enter in translation industry in the future. The CAT's application in translation teaching is the demand of society.

First of all, CAT technology is helpful to satisfy huger social market in the future. Efficiency and quality of translation will both be important standards for future translators. With the development of globalization, increasing quantities of foreign documents will swarm into China, and most of them will be professional, such as engineering technology, commercial contacts, and so on. China's translation market will further expand. In time, manual translation work can no longer meet huge social demand. It is the time that CAT technology comes in handy. As is mentioned above, with the help of translation memory and terminology database, CAT technology is 
qualified enough to finish amount of higher quality work in shorter time. Universities should cultivate useful workers for the society. The students who are trained under the traditional translation teaching mode cannot meet the higher demand of society any more. The CAT's application in translation teaching is imperative.

Besides, CAT is helpful to improve efficiency of translation teaching class. Shorter training time but higher training quality means universities can supply translators to translation market quickly. Translation memory and terminology database are two powerful technical supports in translation. With the assistance of them, large quantity of knowledge could be stored and retrieved rapidly. Students and teachers need not spend lots of time looking up dictionaries or reading relevant books when they translate professional materials. What is more, translation memory is good at processing repetitive information so that students do not have to repeat same or familiar exercise. Saving time does not mean lower quality. Usually, in CAT class, translation memory and terminology database have been set up by teachers or linguists. The storage volume of knowledge is far richer than individual. When student retrieve in CAT tools, they can maybe find more professional and matched words than they expect. They can not only finish their work in high quality, but also improve their vocabulary quickly and unconsciously.

Last but not least, technology and science are the most important tools for us to change the world. We are living in technological age. Merely depending on manpower is not enough to satisfy social needs. Human brain is limited, while technology and science is no bounds. As the rising generation of this era, students should master advanced technology and science firmly. It is a good way not only to meet social demand, but also to promote the development of science and technology. As the advanced technology in translation field, CAT is reasonable to be paid more attention by students and educational field.

\section{CAT Technology Improves Personal Competitive Power}

As technology continues to develop, translators must make an effort to keep abreast of changes and advance, At times, this seems like a full-time job in itself, but it is important if translators wish to remain competitive in the 21th-century marketplace (Bowker, 2002, p. 129).

Higher social demand means fiercer competition for students in the future. To occupy the superior position in career, students should attach enough importance to upgrading personal value in translation. CAT technology can give them assistance.

First of all, CAT technology can help students improve their personal skills. As is mentioned above, with the help of CAT technology, work efficiency will increase outstandingly, which means students who have mastered this technology can finish certain works in shorter time with higher quality than others. According to relevant data, the theoretical maximum of manual translation speed is 5,000 words man-day. With the help of CAT, people can translate twice as fast as the ultimate speed of human being. It is no doubt that shorter work time and higher speed means larger competitive power for students.

Furthermore, for professional translation companies and teams, translators' efficient work will save considerable expense. Table 2 is from the official website of YAXIN (雅信) about the comparison of expense between manual translation and translation with the help of YAXIN CAT software. We can see from the table that the cost of traditional manual translation is more than translation with YAXIN CAT tools. What is more, with the translators' proficiency in using YANXIN CAT tools, the cost reduces to one third per capita. It is far lower than traditional manual translation. 
Table 2

The Cost Comparison Between Manual Translation and the Translation of CAT Tools (QIAN, 2011, p. 109)

\begin{tabular}{lllll} 
& The first month & The second month & The third month & Stable cost per unit \\
\hline Unit cost per capita & Unit cost per capita & Unit cost per capita & (1) \\
YAXIN CAT tools & 0.8 & 1 & 1 & 1 \\
\hline
\end{tabular}

In addition, it is useful to cultivate students ability on teamwork. When facing amounts of difficult translation works, personal power is insignificant. Teamwork is very common in translation industry. Students who major in translation should not only have the consciousness but also have the ability on teamwork. Contemporary translators adopt the mode of teamwork as a result of the large amount of translation tasks and the urgent time. Because of the differences in translators, translating styles and their selection of words, there will be many problems that the style and wording of translation is so inconsistent that the work of revision will stuck in unprecedented difficulties (JIN, 2010, pp. 262-280). Traditional translation teaching mode can provide few opportunities to students to make exercises on teams. With the help of CAT tools, translation is not equal to a struggle by oneself alone any more. Students can share good ideas and discuss problems together on computer so that they can improve skills rapidly. They will realize the importance of teamwork gradually. What is more, they can use the terminology database effectively. It is good for students to improve personal skills on teamwork so that they can easily adapt to the work mode in translation industry in the future.

To sum up, good mastery of CAT tools is enough attractive and competitive to the huge market of translation. It is an urgent task to introduce CAT technology into translation teaching.

\section{The Problems of CAT's Application in Translation Teaching}

It is no doubt that CAT tools can do a favor to translation teaching. However, as a kind of emerging technology, it is not easy for CAT technology to interact perfectly with translation teaching in a short time. There are still some defects of their interaction.

Lacking of professional teachers. In Chinese universities, the big problem for CAT's application in translation teaching is that there is short of professional teachers who are able to operate the latest CAT tools and at the same time have broad academic views.

For one thing, not many teachers go in for CAT teaching. Teaching in CAT technology is still a new field in China. The quantity of teachers is too short to meet the social demand. For another thing, it is not easy to acquire CAT technology. They need to understand and master the use and maintenance of high-tech translation technology and translation tools. They need to know the basic structure and function of computer system, and be acquainted with the latest international information about development and research (LV \& MU, 2007, pp. 35-43).

CAT tools are too expensive to afford. Advanced technology always has surprisingly high price, so does CAT. Table 3 shows the price of some stand-alone CAT tools. In addition, maintenance and repairment is also a generous sum. For students, the tuition on CAT technology is too expensive to afford. It is too excessive to train a student who majors in CAT specialty. Take Peking University for instance, students should pay 40,000 RMB for two-year study, which is twice as expensive as other specialties. 
Table 3

The Price of Some Stand-Alone CAT Tools (ZHOU, 2013, p. 92)

\begin{tabular}{|c|c|c|c|c|}
\hline $\begin{array}{l}\text { CAT tool of stand-alone } \\
\text { version }\end{array}$ & Product classification & Market price & RMB & Remark \\
\hline \multirow{4}{*}{ SDL Trados } & SDL Trados Studio 2011 Freelance & $€ 845$ & $¥ 6744$ & \multirow{4}{*}{$¥ 25100$} \\
\hline & SDL Trados Studio 2011 Professional & $€ 2895$ & $¥ 23105$ & \\
\hline & SDL MultiTerm Desktop 2011 & $€ 250$ & $¥ 1995$ & \\
\hline & SDL Passolo 2011 & $€ 1940$ & $¥ 15483$ & \\
\hline \multirow{2}{*}{ Déjà Vu } & Déjà Vu X2 Professional & $€ 590$ & $¥ 4709$ & \\
\hline & Déjà Vu X2 Workgroup & $€ 1180$ & $¥ 9417$ & \\
\hline \multirow{3}{*}{ Wordfast } & Wordfast Classic (WFC) & $€ 400$ & $¥ 3192$ & \\
\hline & Wordfast Pro (WFP) & $€ 400$ & $¥ 3192$ & \\
\hline & $\begin{array}{l}\text { Wordfast Studio (Classic } \\
\text { and Pro) }\end{array}$ & $€ 500$ & $¥ 3990$ & \\
\hline \multirow{2}{*}{ YAXIN CAT } & YAXIN CAT 4.0 PRO version & & $¥ 5800$ & \\
\hline & YAXIN CAT 4.0 Standard version & & $¥ 3600$ & \\
\hline
\end{tabular}

Domestic academia has not attached enough importance to CAT tools. Usually, it will spend a lot of time for people in accepting and paying attention to a new technology. Therefore, CAT technology has not carried weigh in translation teaching today. Only a few domestic universities offer courses in CAT technology. Master's degree in translation is common in foreign language departments in China. However, only Peking University and the Chinese University of Hong Kong can offer the special master's degree in CAT. Some others can offer few courses about CAT technology such as Harbin Engineering University. While most of universities have not offered any courses about CAT technology. The neglect results in the reduction in students learning opportunities and the drawback in translation field.

\section{The Suggestion of CAT's Application in Translation Teaching}

As is mentioned above, the application of CAT in translation teaching is the demand of society and translation industry. The emerged problems should be attached enough concern and solved energetically. It needs great efforts from society.

First of all, universities should hold more relevant extra curricular activities. CAT is an emerging and advanced technology which has not been acknowledged by most students. Various well-designed activities can give students more opportunities to know about CAT technology. It is also a good way to motivate students' interest and attract them to study on CAT technology further in the future. In 2014, Peking University held a summer camp to call for undergraduates paying more attention to this leading technology and gained favorable feedback. It is a good example for other universities.

Besides, academia should encourage qualified scholars to study advanced technology and invent CAT tools independently. At present, Trados and Déjà Vu are two representative CAT tools in the world. Indigenous CAT tools are still deficient in technology. YAXIN CAT and Snowman CAT developed rapidly in recent years, but they are still not mature enough to occupy international market. To research and develop CAT tools independently can not only make a profit, but also reduce the cost for universities in building professional classrooms so that schools can transmit more qualified people for society. 
Furthermore, universities need build professional CAT classrooms. Theoretical knowledge for CAT technology is very important, at the same time, practical knowledge is also requisite. XU Bin believes that to have a deeper study of CAT, we have to not only learn translation theory but also be equipped with practical experience; what is more, we need to have "the ability of computer operation and software using \& evaluation" (quoted in CHEN, 2011, p. 15). As is mentioned above, because of the limitation of economic and technical circumstances, though some schools offered CAT technology courses, they do not have professional classrooms for students to operate practically. Armchair strategy is far from enough for study in CAT technology. Universities should build professional CAT classrooms as soon as possible, and the classrooms should be opened for students even during spare time. Enough exercise time and combination of theoretical and practical knowledge is useful enough to improve students' personal skill.

Finally, leading universities and research institutions should undertake the responsibility to train men for profession. The trained targeted group could be not only students, but also teachers. In China, some teachers are experienced enough in teaching and translation, but they do not have a good knowledge of CAT technology or computer operation. Training such groups will spend less time than training fresh students. What is more, the trained and qualified teachers could solve the problem of lacking of teachers as quickly as possible.

\section{Conclusion}

With the rapid development of science and technology, the importance of CAT technology has manifested gradually. Most existent translation industries regard the skill of operating CAT tools expertly as a key standard in employment. It is no doubt that students majoring in translation have to acquire more technologies to improve their competence and meet the demand of translation market.

To sum up, CAT technology will play more important role in translation. CAT technology has an enormous potential in development. New CAT applications keep emerging in recent years, and the technology tend to mature gradually. It is necessary for students to master expertly. With the increasingly attention paid, the interaction between CAT and translation teaching will make great progress in the future.

\section{References}

Bowker, L. (2002). Computer-aided translation technology: A practical introduction. Ottawa: University of Ottawa Press.

CHEN, L. L. (2011). The course design of computer-aided translation and MTI (Master dissertation, Shandong Normal University, Jinan).

JIN, G. S. (2010). Analysis on present situation and the development trend of the of computer-aided translation technology. Journal of Shenyang Architecture and Civil Engineering University (Natural Science), 3, 262-280.

LI, M., \& ZHU, X. M. (2013). New exploration on posting editing automation of English-Chinese machine translation. Chinese Translators Journal, 4, 83-87.

LV, L. S., \& MU, L. (2007). Computer-aided translation and translation teaching. Journal of Foreign Language World, 3, 35-43.

QIAN, D. X. (2011) . Computer-aided translation. Beijing: Foreign Language Teaching and Research Press.

REN, J. J. (2010). Computer-aided translation teaching by means of modern information technology. Guide to Science \& Education, 3,15 .

Machine translation (n.d.). In Wikipedia. Retrieved from https://en.wikipedia.org/wiki/Machine_translation

ZHOU. X. H. (2013). Computer-aided translation teaching: Methods and resources (Master dissertation). Chinese Translators Journal, 4, 91-95.

ZUO, L. (2010). Computer-aided translation tools and their application in translation teaching. Journal of Mudanjiang Institute of Education, 1, 136-137. 